\title{
The Location-allocation Decision under The Dynamic Increment of Demand for Selecting The Local Distribution Centers to Face Sumatra Megathrust: Study Case of Padang City
}

\author{
Liperda Rahmad Inca", Sirivongpaisal Nikorn ${ }^{\#}$ \\ \# Department of Industrial Engineering, Prince of Songkla University, Hatyai, Thailand \\ E-mail: inca.liferda@gmail.com,nikorn.s@psu.ac.th
}

\begin{abstract}
The efforts of providing effective relief assistance in the aftermath of the disaster is prominent to prevent losses and suffering. During the emergency response, the level of preparedness becomes a decisive factor to obtain an immediate countermeasure in order to enhance the capability and to reduce the impact caused by the disaster. Due to its vital role as a transit point to manage large inflow and outflow of the relief commodities, the location-allocation decision to select the appropriate Local Distribution Centers (LDCs) is essential. This research proposes the location-allocation planning for encountering Sumatra Megathrust during 72 hours of the critical period. The dynamic increment of demand over the planning period is considered as a constraint to obtain the set of appropriate LDCs to be established per day. The consideration regarding the expected impassable paths based on the worst case tsunami inundation scenario is acknowledged to ensure the proper access for distributing the relief aids. This work utilizes Geographical Information Systems (GIS) with the maximum coverage analysis to generate the set of alternative LDCs per day. The effectiveness of the alternative LDCs is measured by calculating the opening cost and transportation cost. The finding recommends two LDCs to be opened in the first two days, and three LDCs are considered to be established on the third day. The total costs of the LDCs establishment per day are 1369.05 USD, 669.85 USD, and 1126.53 USD. The depiction of the selected depots-recipient counterparts is provided to acquire the spatial information of the study area.
\end{abstract}

Keywords - relief assistance; location-allocation; LDCs; GIS; Sumatra megathrust.

\section{INTRODUCTION}

In the aftermath of a disaster event, dispatching relief aids is crucial to prevent losses and suffering. Uncertainties and complexities are classic problems to be faced by the relief aid managers in order to perform rapid-prompt assistance. The quick-effective relief efforts should be executed under careful consideration. Therefore, the arrangement of decent emergency response is essential to the relief stakeholders in order to meet the beneficiaries' satisfaction.

During the emergency response, the level of preparedness becomes a decisive factor to enhance the capability and to reduce the impact caused by disaster [1]. In this phase, the construction of the physical network, information systems, and collaboration among the stakeholders are established [2]. In particular, the preparedness stage must encompass a logistical activity planning since it contributes to $80 \%$ of the disaster relief cost [1]. During this stage, the humanitarian logistics mainly focuses on determining the strategic locations as well as the relief goods quantities to be prepositioned [3]. The right decision on the location- allocation will strongly affect the effectiveness and efficiency of the relief efforts.

In recent years, many researchers have sought to determine the suitable location-allocation model in the humanitarian relief context. The use of Geographic Information System (GIS) is widely applied in emergency management operations by utilizing the spatial information to represent the real condition of a system. With regard to the preparedness phase which may take a lot of time and money, GIS is required as the decision-support tool to analyze the potential hazard and organizes encountering reaction [4]. In 2009, Almeida et al., [5] developed the GISbased decision support system (DSS) for the fire evacuation planning, namely SIGUrb. The selection of the emergency shelters referred to the four points of interest; travel distance, the probability of the difficult path, fire risk at the shelters, and evacuation time. The mixed integer linear programming model with a multi-objective approach to locating the municipal evacuation shelters by extending the work of Almeida et al. was taken into account by Rodrigues et al., [6]. The authors proposed the secondary (backup) evacuation path by applying the weighting method. Another study of 
optimizing location-allocation after an occurrence of calamities accompanied by its secondary hazard is contained in [7]. Three indicators, including accessibility, safety, and effectiveness are considered in their paper. The p-center model is used to determine the location-allocation optimization. The implementation of GIS as a useful decision-making tool in disaster management is also provided in the work of Rodriguez et al., [8]. The effectiveness of the stand-alone location-allocation model and the GIS-based location allocation is compared in their research. In Saedian et al., [9], GIS was used in the preparation stage to analyze the gravity centers of the parcel and the relief centers in order to obtain its geographical coordinate to be further utilized as input for the metaheuristic algorithms.

This research intends to generate the location-allocation decision which prevails at the strategic level of the humanitarian logistics. This study takes into account the effect of the dynamic increment of demand to the decision of locating the Local Distribution Centers (LDCs) as well as allocating the proper relief aids to face the probable hazard Sumatra Megathrust. Since 72 hours after the disaster occurred is crucial [1], this work takes into consideration the short-term period to design the desirable location-allocation planning. A maximum coverage model is applied to generate the set of alternative LDCs by considering the daily required demand with the use of Geographic Information System (GIS). In addition, the consideration of the accessible path is actualized by avoiding the expected inundation area based on the worst-case inundation scenario developed by the local government. Ultimately, the total cost which consists of the opening cost and the transportation cost is calculated to determine the LDCs to be built per day.

The remainder of this paper is structured as follows. Section 2 of this paper presents the materials and method of research. The computational study including the data preparation and the results and analysis is discussed in section 3. Finally, section 4 contains the conclusions and the improvement for future research.

\section{MATERIALS AND METHOD}

This section discusses the source of the potential hazard, the study area, the problem identification, the demand characteristic, and the modeling approach.

\section{A. Course of Event}

The Sumatra Megathrust issue is one of the most threatening hazards in the future. The prediction of the giant frequency of earthquake with $8 \mathrm{M}$ or even more massive and may trigger a huge tsunami [10]. The tsunami wave moving from the epicenter will then quickly traverse the open ocean from tens to thousands of kilometers away and may inundate the coastal areas for several kilometers, depending on its topography. The wave height increases along with its move to the coastal area with velocity reaching hundreds kilometer per hour. The tsunami inundation may take several hours to recede and brings the material from the shoreline to the ocean. The impact of this scare event may affect the loss of life, material destruction, and natural environment.

\section{B. Study Area}

In this research, the focus is aimed at designing a location-allocation decision in Padang City for at least two significant reasons. Firstly, Padang is predicted to be the city with the most significant amount of affected people as an effect of this hazardous disaster. This prophecy reaches 55\% of the total affected victims in West Sumatra, which is expected to be 921,349 inhabitants [10]. Secondly, based on the experience of the last extreme earthquake in 2009, the tardiness of the supplies arrival and the inequalities of the relief aids fulfillment in Padang City became the major issue faced by the relief managers. Hence, the comprehensive planning of the location-allocation decision in Padang City is strongly needed to meet the beneficiaries' necessities rapidly.

\section{Problem Identification}

The intended problems arise at the last mile stage of the humanitarian logistics activities. As the requirement of the relief goods increases suddenly after the tsunami event, the stakeholders and the relief agencies begin to deliver the required commodities to the affected area. The need for the Local Distribution Centers (LDCs) as a transit point is crucial in order to organize the massive inflow and outflow of relief commodities. An LDC can be a tent, prefabricated building, or existing building which is usually established in the post-disaster event and serve a certain number of demand points. The relative distance of an LDC to its service regions is another factor for determining the location of LDC. Moreover, the dynamic increment of the demand requirement should be considered to be sufficiently suited to the number of LDCs to be established. The main task is to spatially analyze the proper location-allocation of the leastcost LDCs upon the relative opening cost and total handling cost.

\section{Demand Characteristic}

In order to deal with the consequences of the future Sumatra Megathrust hazard, the local government has designed the evacuation assignment procedure for sheltering from the tsunami hazard. The zoning technique based on the residential terrain is applied to classify the potential designated shelter during the evacuation process. The escaping assignment is held in the immediate aftermath of the earthquake within 20 minutes until the tsunami wave inundates the area. During this period, some zones are assigned to straightly escape to the refugee camps in the safe zone while some of them are directed to the vertical evacuation shelters. The post-inundation assignment, on the other hand, is actuated when the tsunami wave recedes from inundating the area by assigning the evacuees who had sheltered from the tsunami inundation in the vertical shelter to move to the refugee camps. There are 184 proposed vertical evacuation buildings and 12 refugee camps to be utilized for sheltering from the tsunami.

The required quantity of the consumable items can be implied from the arrival of victims at an assigned refugee camp [11]. An illustrative example in Fig. 1 explains the two terms arrival pattern of the tsunami victims based on the evacuation assignment. Since the number of victims in the first term assignment are directed to escape to the given refugee camps straightly, the amount of the required supplies 
remains constant during the emergency period. On the other hand, in the second term arrival, this research adopts the Sshaped curve, which also used by Rawls et al., [11], to represent that the cumulative arrival rate evolves over time. As mentioned before, in this research the planning horizon will be set to be 72 hours due to its significance in minimizing losses and suffering. The peak point of the cumulative arrival in each day is used to assess the demand required per day. The percentage of the first term arrival occupies the total assigned victims of this term since they are obligated to straightly evacuate to the designated refugee camps during the escaping period. Referring to Song and Yan [12], the peak point ratio to the total assigned victims in the second term assignment following the Sigmoid curve is defined by $13.588 \%, 56.161 \%$, and $91.256 \%$, respectively for each consecutive day.

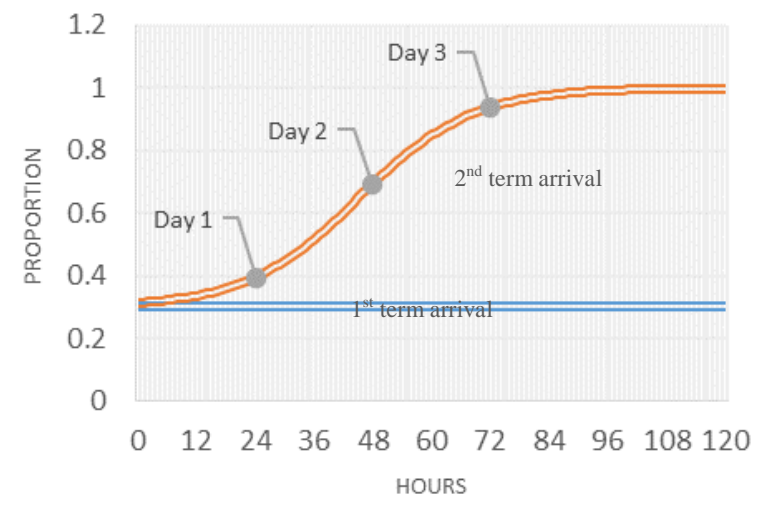

Fig. 1 Victims' arrival pattern

\section{E. Modeling Approach}

This section generates a systematic methodology to be utilized to obtain the best-suited location-allocation of LDCs per day. As depicted by Fig. 2, the set of demand points, the daily weighted factor of each demand points based on the daily requirements, LDCs candidates, and the road network barriers are set as input for analyzing the location-allocation decision. The location-allocation feature in GIS tool is employed to obtain a set of alternative LDCs by using maximum coverage analysis. The objective function, the total opening cost, and total transportation cost are going to be minimized by each set of alternative LDCs. The opening cost belongs to the total fixed cost obtained to establish an LDC with a specific capacity. A temporary LDC such as tent has a limited capacity to store a certain number of relief goods. The excessive freight will affect the establishment of a new repository. The transportation cost, on the other hand, corresponds to three cost components, including loadingunloading cost, shipment cost, and labor cost. Finally, the set of LDCs with the least-cost is assigned to be established. This research assumes the sustain-utilization of an LDC by assigned the selected LDCs in particular as the required LDCs in the next day with the consideration to its sufficiency to storage the arriving commodities.

\section{RESULTS AND DISCUSSION}

This section firstly discusses the data involved in this research including the research assumption. Subsequently, the results and analysis are presented to generate the location-allocation decision based on the minimum total fixed opening cost and transportation cost.

\section{A. Data preparation and research assumption}

Based on the evacuation plan designed by the local government, there are 12 designated refugee camps (RC) to accommodate the total expected number of 437,860 inhabitants. In this research, the refugee camps are also used as the LDCs candidates. Three types of relief items are considered including rice, noodle, and preserved food with standard fulfillment per person per day $400 \mathrm{gr}, 95 \mathrm{gr}$, and $200 \mathrm{gr}$, respectively [13]. The fixed cost of opening LDC with volume capacity $168 \mathrm{~m} 3$ is 500 USD. On the other hand, the transportation cost components comprise three main components, including loading-unloading cost (2.56 USD per ton), shipment cost (0.313 USD per $\mathrm{km}$ per ton), and labor cost (3 USD per trip). In addition, the 6-wheel vehicle with capacity 4 ton is utilized to distribute the relief aids.

Table 1 shows the expected victims arrival at the given RCs per day. The calculation of the cumulative arrival is based on the and the arrival ratio by considering the victims' arrival pattern. The constant number of the $1^{\text {st }}$ term arrival is summarized with the relative value of the S-shaped pattern per day from the $2^{\text {nd }}$ term arrival to obtain the total number of victims requiring the relief aids.

\section{B. Results and analysis}

This subsection presents the results and analysis of the data calculation. The daily required demand is calculated based on the expected victims' arrival per day. The geographic condition of the study area is carried out to spatially portray the location of the existing RCs and LDCs candidates. The location-allocation computation is displayed to choose the minimum total cost of the LDCs establishment.

\section{1) Daily required demand and space requirements}

The total delivery amount and the required space for holding the relief aids per day are presented in Table 2 which is calculated based on the expected victims' arrival in Table 1 by considering the standard of the relief aid fulfillment and volume of each relief item referring to the work of Patrisina et. al., [14]. The amount of the delivered items is required for calculating the transportation cost while the required space of storing the relief aids will be used to determine the opening cost of LDC. The daily delivery amount is obtained from summarizing the total amount of the required rice, noodle, and preserved food per day. Meanwhile, the space requirement the relief commodities are $0.031 \mathrm{~m} 3$ for $30 \mathrm{~kg}$ of rice, $0.020 \mathrm{~m} 3$ for 40 packs of noodle, and $0.005 \mathrm{~m} 3$ for 12 cans of preserved food [13].

\section{2) Location-allocation decision}

This location allocation decision utilizes ArcMap 10.2 with the maximum coverage analysis to generate a set of alternative LDCs per day. The algorithm used in GIS for solving the facility location problem comprises the integration between five heuristic methods in order to obtain the near-optimal solution with a relatively short optimization time.

The daily required amount from Table 2 is used as input for calculating the desirability of a demand point to be visited. In addition, the expected impassable roads based on 


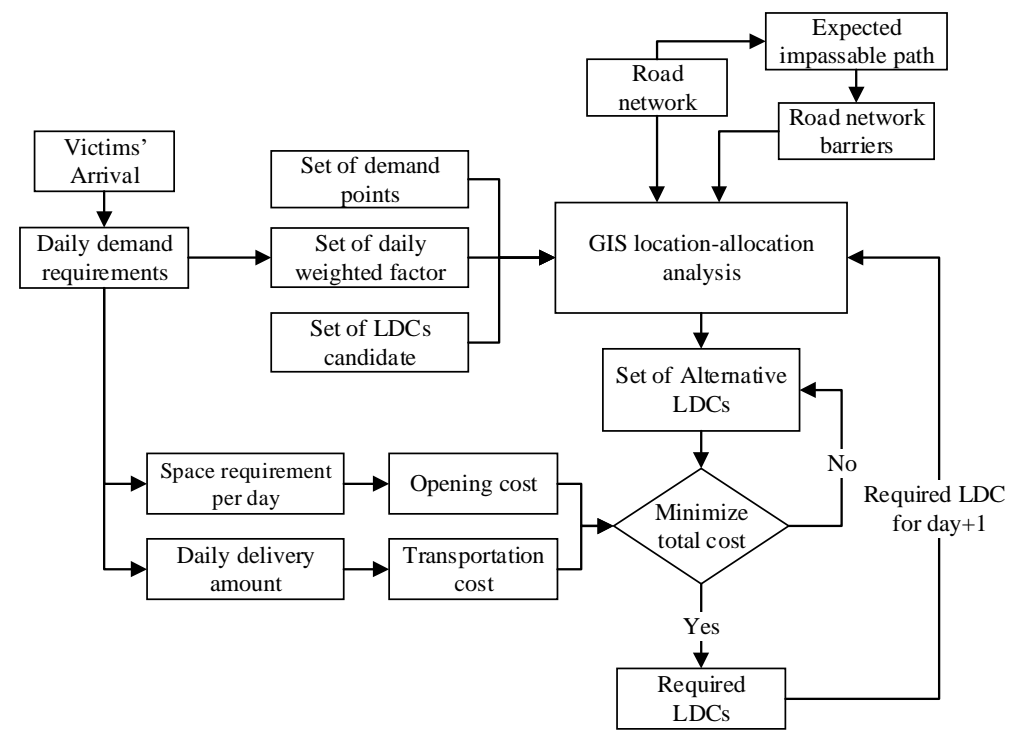

Fig. 2 Research methodology

TABLE I

EXPECTED Victims ARRIVAL at REFUGEe CAMPS

\begin{tabular}{|c|l|c|c|c|c|c|c|}
\hline \multirow{2}{*}{$\begin{array}{c}\text { Refugee } \\
\text { Camp }\end{array}$} & \multirow{2}{*}{ Location } & \multirow{2}{*}{$\begin{array}{c}\text { Expected } \\
\text { Victims }\end{array}$} & & \multicolumn{2}{|c|}{ Moving Assignment } & \multicolumn{2}{|c|}{ Expected Victims Arrival } \\
\cline { 6 - 8 } & & & $\mathbf{1}^{\text {st }}$ Term & $\mathbf{2}^{\text {nd }}$ Term & $\mathbf{2 4}$ Hrs & $\mathbf{4 8 ~ H r s}$ & $\mathbf{7 2}$ Hrs \\
\hline A1 & Batipuh Panjang & 19,978 & 10,154 & 9,824 & 11,489 & 15,672 & 19,119 \\
\hline A2 & Bukit Anak Aia & 24,797 & 5,473 & 19,324 & 8,099 & 16,326 & 23,107 \\
\hline B1 & Koto Pulai & 21,233 & 7,668 & 13,565 & 9,511 & 15,286 & 20,047 \\
\hline B2 & Balai Gadang & 6,603 & 1,101 & 5,503 & 1,848 & 4,191 & 6,122 \\
\hline C1 & Koto Panjang Ikua Koto & 12,614 & 3,806 & 8,808 & 5,003 & 8,753 & 11,844 \\
\hline D1 & Municipality office & 18,801 & 18,801 & - & 18,801 & 18,801 & 18,801 \\
\hline D2 & TVRI office, by pass & 56,398 & 17,967 & 38,431 & 23,189 & 39,550 & 53,038 \\
\hline E1 & Gunung Pangilun & 80,684 & 11,254 & 69,431 & 20,688 & 50,247 & 74,614 \\
\hline F1 & Sungai Sapih & 32,625 & 13,242 & 19,383 & 15,876 & 24,128 & 30,930 \\
\hline G1 & Kubu Marapalam & 106,327 & 32,414 & 73,913 & 42,458 & 73,925 & 99,864 \\
\hline H1 & Teluk Kabung Utara & 16,411 & 1,144 & 15,267 & 3,219 & 9,718 & 15,076 \\
\hline I1 & Banuaran nan XX & 41,389 & 3,854 & 37,536 & 8,954 & 24,934 & 38,107 \\
\hline & Total & 437,860 & 126,879 & 310,982 & 169,135 & 301,530 & 410,670 \\
\hline
\end{tabular}

the expected inundation is considered. Fig. 3 deliberates the analysis of the study area based on the worst inundation scenario developed by the government. The road access connecting to refugee camp $\mathrm{H} 1$ is predicted to encounter severe damage. Hence, the delivery activities to this point are assumed to use ship by replacing the demand point of $\mathrm{H} 1$ to the ship loading point (LP). Meanwhile, the damaged access to point A1, A2, and B1 is assumed to be restored in the aftermath of the disaster.

The effectiveness of the resulted solution from GIS is examined by calculating the total cost which comprises the opening cost and transportation cost of transporting a specific amount of goods from the LDCs to the assigned demand points. This work also considers the sustained utilization of the selected LDCs to be required in the upcoming days as long as the required LDCs still have

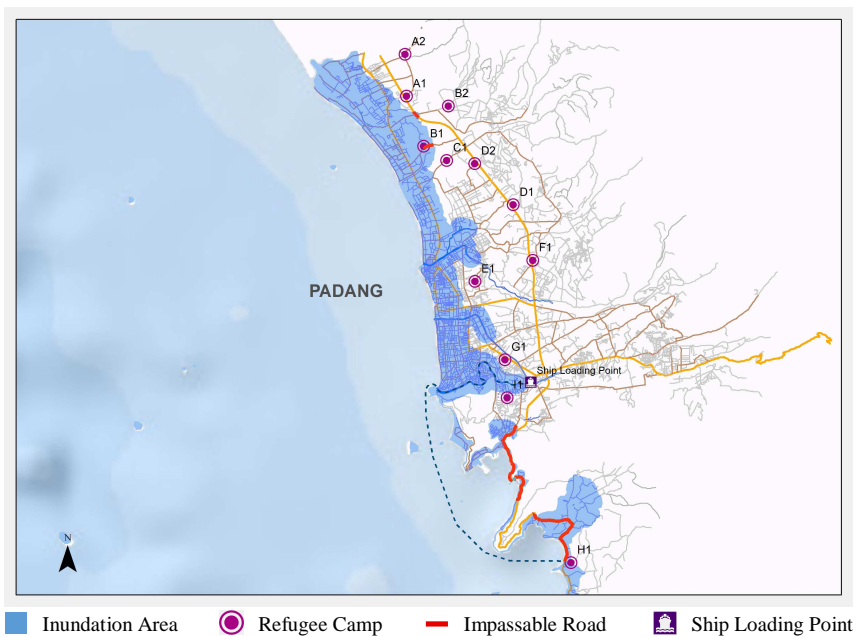

Fig. 3 Spatial analysis 
a sufficient capacity to store the relief aids without any expense for the opening cost. Finally, the LDCs with the least total cost per day will be selected as the recommended LDCs to be opened.

As shown in Table 3, the location-allocation scenario with two depots, LDC D2, and LDC G1 is considered to be opened in the first day since this combination obtains the least total cost, 1,369.047 USD. The selected LDCs on the first day, LDC D2 and LDC G1, is used as the required LDCs in the second day. Since the capacity of both LDCs is still sufficient for stockpiling the relief commodities (less than $168 \mathrm{~m} 3$ ), the total cost of utilizing these two LDCs in the second day obtains the minimum result, 669.852 USD. In the third day, however, the expense for opening another storage in each LDC D2 and LDC G1 is charged due to the inadequate storage to store the relief aids. By adding one more LDC, the total cost produced yields the minimum cost, $1,126.533$ USD. Hence, the total cost of the proposed LDCs for the three consecutive days will spend 3,165.43 USD.

TABLE II

Total DeliVery Amount AND SPACE REQUIREMENTS

\begin{tabular}{|c|l|c|c|c|c|c|c|}
\hline \multirow{2}{*}{$\begin{array}{c}\text { Refugee } \\
\text { Camp }\end{array}$} & \multicolumn{2}{|c|}{ Location } & \multicolumn{2}{|c|}{ Delivery Amount (Ton) } & \multicolumn{3}{c|}{ Total Space Requirements $\left(\mathbf{m}^{\mathbf{3}}\right)$} \\
\cline { 3 - 8 } & & $\mathbf{2 4}$ Hrs & $\mathbf{4 8 ~ H r s}$ & $\mathbf{7 2 ~ H r s}$ & $\mathbf{2 4}$ Hrs & $\mathbf{4 8}$ Hrs & $\mathbf{7 2}$ Hrs \\
\hline A1 & Batipuh Panjang & 7.99 & 10.89 & 13.29 & 18.30 & 24.92 & 30.39 \\
\hline A2 & Bukit Anak Aia & 5.63 & 11.35 & 16.06 & 12.88 & 25.96 & 36.76 \\
\hline B1 & Koto Pulai & 6.61 & 10.62 & 13.93 & 15.13 & 24.30 & 31.89 \\
\hline B2 & Balai Gadang & 1.28 & 2.91 & 4.25 & 2.95 & 6.68 & 9.75 \\
\hline C1 & Koto Panjang Ikua Koto & 3.48 & 6.08 & 8.23 & 7.97 & 13.92 & 18.83 \\
\hline D1 & Municipality office & 13.07 & 13.07 & 13.07 & 29.90 & 29.90 & 29.90 \\
\hline D2 & TVRI office, by pass & 16.12 & 27.49 & 36.86 & 36.88 & 62.88 & 84.30 \\
\hline E1 & Gunung Pangilun & 14.38 & 34.92 & 51.86 & 32.89 & 79.84 & 118.57 \\
\hline F1 & Sungai Sapih & 11.03 & 16.77 & 21.50 & 25.25 & 38.36 & 49.18 \\
\hline G1 & Kubu Marapalam & 29.51 & 51.38 & 69.41 & 67.50 & 117.47 & 158.69 \\
\hline H1 & Teluk Kabung Utara & 2.24 & 6.75 & 10.48 & 5.13 & 15.46 & 24.00 \\
\hline I1 & Banuaran nan XX & 6.22 & 17.33 & 26.48 & 14.25 & 39.65 & 60.59 \\
\hline & Total & 117.55 & 209.56 & 285.42 & 269.03 & 479.33 & 652.83 \\
\hline
\end{tabular}

TABLE III

Total DELIVERy AMOUNT AND SPACE REQUiREMENTS

\begin{tabular}{|c|c|c|c|c|c|c|c|c|c|}
\hline \multirow[b]{2}{*}{ Day } & \multirow[b]{2}{*}{ Scenario } & \multirow[b]{2}{*}{$\begin{array}{l}\text { Alternative } \\
\text { LDCs }\end{array}$} & \multirow[b]{2}{*}{ Recipients } & \multirow[b]{2}{*}{$\begin{array}{c}\text { Total Space } \\
\text { Requirements } \\
\left(\mathbf{m}^{\mathbf{3}}\right)\end{array}$} & \multirow[b]{2}{*}{$\begin{array}{c}\text { Opening } \\
\text { Cost } \\
\text { (USD) }\end{array}$} & \multicolumn{3}{|c|}{ Transportation Cost } & \multirow[b]{2}{*}{$\begin{array}{r}\text { Total } \\
\text { Cost } \\
\text { (USD) }\end{array}$} \\
\hline & & & & & & $\begin{array}{c}\text { Loading } \\
\text { Unloading } \\
\text { Cost (USD) } \\
\end{array}$ & $\begin{array}{c}\text { Shipment } \\
\text { Cost } \\
\text { (USD) } \\
\end{array}$ & $\begin{array}{l}\text { Labor } \\
\text { Cost } \\
\text { (USD) } \\
\end{array}$ & \\
\hline \multirow{6}{*}{1} & 1 Depot & LDC F1 & $\begin{array}{l}\mathrm{A} 1, \mathrm{~A} 2, \mathrm{~B} 1, \mathrm{~B} 2, \mathrm{C} 1, \\
\mathrm{D} 1, \mathrm{D} 2, \mathrm{E} 1, \mathrm{~F} 1, \mathrm{G} 1,\end{array}$ & 243.782 & 1000 & 272.7 & 246.3 & 96.0 & 1615.0 \\
\hline & \multirow[t]{2}{*}{2 Depot } & LDC D2 & $\begin{array}{c}\mathrm{A} 1, \mathrm{~A} 2, \mathrm{~B} 1, \mathrm{~B} 2, \mathrm{C} 1, \\
\mathrm{D} 1, \mathrm{D} 2, \mathrm{~F} 1\end{array}$ & 112.382 & \multirow[t]{2}{*}{1000} & \multirow[t]{2}{*}{184.1} & \multirow[t]{2}{*}{118.9} & \multirow[t]{2}{*}{66.0} & \multirow[t]{2}{*}{1369.0} \\
\hline & & LDC G1 & E1, G1, LP, I1 & 52.272 & & & & & \\
\hline & \multirow{3}{*}{3 Depot } & LDC D2 & $\begin{array}{c}\mathrm{A} 1, \mathrm{~A} 2, \mathrm{~B} 1, \mathrm{~B} 2, \mathrm{C} 1, \\
\mathrm{D} 1, \mathrm{D} 2\end{array}$ & 87.130 & \multirow{3}{*}{1500} & \multirow{3}{*}{147.3} & \multirow{3}{*}{82.5} & \multirow{3}{*}{54.0} & \multirow{3}{*}{1783.8} \\
\hline & & LDC E1 & $\mathrm{E} 1, \mathrm{~F} 1$ & 25.252 & & & & & \\
\hline & & LDC G1 & G1, LP, I1 & 19.380 & & & & & \\
\hline \multirow{9}{*}{2} & \multirow[t]{2}{*}{2 Depot } & LDC D2 & $\begin{array}{c}\text { A1, A2, B1, B2, C1, } \\
\text { D1, D2, F1 }\end{array}$ & 164.033 & \multirow[t]{2}{*}{0} & \multirow[t]{2}{*}{334.6} & \multirow[t]{2}{*}{224.3} & \multirow[t]{2}{*}{111.0} & \multirow[t]{2}{*}{669.8} \\
\hline & & LDC G1 & E1, G1, LP, I1 & 134.953 & & & & & \\
\hline & \multirow{3}{*}{3 Depot } & LDC D2 & $\begin{array}{c}\mathrm{A} 1, \mathrm{~A} 2, \mathrm{~B} 1, \mathrm{~B} 2, \mathrm{C} 1, \\
\mathrm{D} 1, \mathrm{D} 2\end{array}$ & 125.673 & \multirow{3}{*}{500} & \multirow{3}{*}{245.2} & \multirow{3}{*}{139.6} & \multirow{3}{*}{84.0} & \multirow{3}{*}{968.8} \\
\hline & & LDC E1 & $\mathrm{E} 1, \mathrm{~F} 1$ & 38.360 & & & & & \\
\hline & & LDC G1 & G1, LP, I1 & 55.115 & & & & & \\
\hline & \multirow{4}{*}{4 Depot } & LDC A1 & $\mathrm{A} 1, \mathrm{~A} 2, \mathrm{~B} 2$ & 57.553 & \multirow{4}{*}{1000} & & & & \\
\hline & & LDC D2 & $\mathrm{B} 1, \mathrm{C} 1, \mathrm{D} 1, \mathrm{D} 2$ & 68.120 & & 2173 & 082 & 750 & 13005 \\
\hline & & LDC E1 & E1, F1 & 38.360 & & 217.3 & 98.2 & 15.0 & 1390.5 \\
\hline & & LDC G1 & G1, LP, I1 & 55.115 & & & & & \\
\hline
\end{tabular}




\begin{tabular}{|c|c|c|c|c|c|c|c|c|c|}
\hline \multirow{9}{*}{3} & \multirow[t]{2}{*}{2 Depot } & LDC D2 & $\begin{array}{c}\mathrm{A} 1, \mathrm{~A} 2, \mathrm{~B} 1, \mathrm{~B} 2, \mathrm{C} 1, \\
\mathrm{D} 1, \mathrm{D} 2, \mathrm{~F} 1\end{array}$ & 206.693 & \multirow[t]{2}{*}{1000} & \multirow[t]{2}{*}{458.6} & \multirow[t]{2}{*}{311.1} & \multirow[t]{2}{*}{153.0} & \multirow[t]{2}{*}{1922.7} \\
\hline & & LDC G1 & E1, G1, LP, I1 & 203.151 & & & & & \\
\hline & \multirow{3}{*}{3 Depot } & LDC D2 & $\begin{array}{c}\mathrm{A} 1, \mathrm{~A} 2, \mathrm{~B} 1, \mathrm{~B} 2, \mathrm{C} 1, \\
\mathrm{D} 1, \mathrm{D} 2\end{array}$ & 157.517 & \multirow{3}{*}{500} & \multirow{3}{*}{325.9} & \multirow{3}{*}{186.7} & \multirow{3}{*}{114.0} & \multirow{3}{*}{1126.5} \\
\hline & & LDC E1 & E1, F1 & 49.176 & & & & & \\
\hline & & LDC G1 & G1, LP, I1 & 84.584 & & & & & \\
\hline & \multirow{4}{*}{4 Depot } & LDC A1 & $\mathrm{A} 1, \mathrm{~A} 2, \mathrm{~B} 2$ & 46.509 & \multirow{4}{*}{1000} & \multirow{4}{*}{291.8} & \multirow{4}{*}{131.8} & \multirow{4}{*}{102.0} & \multirow{4}{*}{1525.6} \\
\hline & & LDC D2 & $\mathrm{B} 1, \mathrm{C} 1, \mathrm{D} 1, \mathrm{D} 2$ & 80.621 & & & & & \\
\hline & & LDC E1 & E1, F1 & 49.176 & & & & & \\
\hline & & LDC G1 & G1, LP, I1 & 84.584 & & & & & \\
\hline
\end{tabular}

The spatial information of the selected LDCs-recipients in the first two days is presented in Fig. 4. In these two days, the respective LDCs-recipients remain the same. However, in order to accommodate the incremental change of the demand needs, three LDCs are required to be built on the third day, as shown in Fig. 5.

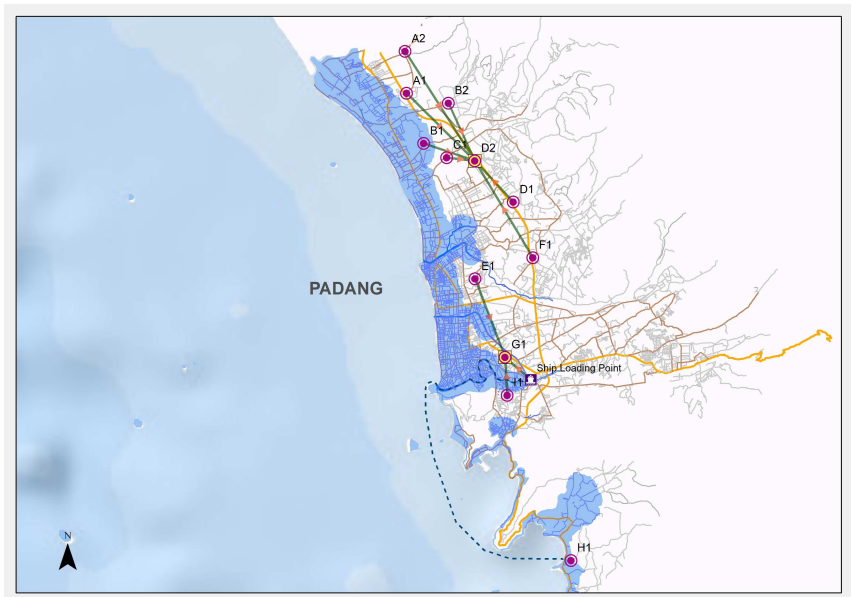

Fig. 4 The location-allocation decision day-1 and day- 2

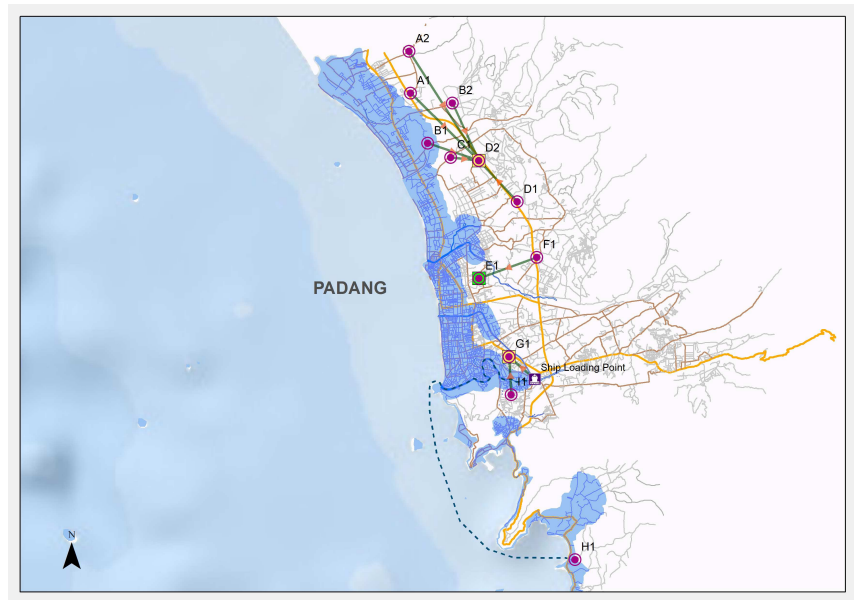

Fig. 5 The location-allocation decision day-3

\section{CONCLUSIONS}

The deliberation on the accountability and quality of the relief efforts is essential for the relief actors to design an appropriate location-allocation strategy. A correct locationallocation decision during the preparedness stage is significant to provide better quality assistance in the response phase. In order to find more flexible locationallocation planning, this work incorporates the dynamic increment of the demand needs to select the appropriate number of LDCs per day with the minimum opening cost and transportation cost. This research is intended to encounter the tremendous impact caused by the potential disaster, Sumatra Megathrust. The short term fulfillment is employed in this work due to its crucial impact on preventing the losses and suffering. This research utilizes the use of GIS to generate the set of alternative LDCs with nearoptimal solutions. In this work, the potential impassable roads are considered. This research recommends the proper daily location-allocation planning, with LDC D2 and LDC G1 are opened for the first and second day, and three LDCs, LDC D2, LDC E1, and LDC G1 are selected to operate in the third day. The total cost for opening these facilities and allocating the relief demands during the 3 days of the emergency period is $3,165.43$ USD. Ultimately, this finding is essential for the relief aid managers to organize the prompt-appropriate relief response and provide welfare among victims. The implementation of this application for the other affected areas may achieve a better preparedness level to deal with the hazardous disaster Sumatra Megathrust.

Despite its usefulness in determining the least-cost result for location-allocation decision by considering the increment of demand, this research still encompasses several limitations. The wider scope of application in term of the study area and the type of relief aids to be supplied is necessary to provide a thorough analysis of the relief preparedness decision. In addition, the uncertainties in term of victims' arrival, the time required for restoring the expected damaged roads, the resource utilization and the vehicle velocity would complicate the relief decision making. The fairness concept on fulfilling the demand needs is also another challenge to be accomplished in order to meet the victims' satisfaction.

\section{REFERENCES}

[1] L. N. Van Wassenhove, "Blackett memorial lecture humanitarian aid logistics: Supply chain management in high gear," J. Oper. Res. Soc., vol. 57, no. 5, pp. 475-489, 2006.

[2] A. Cozzolino, S. Rossi, and A. Conforti, "Agile and lean principles in the humanitarian supply chain: The case of the United Nations World Food Programme," J. Humanity. Logist. Supply Chain Manag., vol. 2, no. 1, pp. 16-33, 2012.

[3] B. Balcik and B. M. Beamon, "Facility location in humanitarian relief," Int. J. Logist. Res. Appl., vol. 11, no. 2, pp. 101-121, 2008.

[4] M. Milenković and D. Kekic, "Using GIS in Emergency Management," Proc. Int. Sci. Conf. - Sint. 2016, no. April, pp. 202207, 2016.

[5] L. Alçada-Almeida, L. Tralhão, L. Santos, and J. CoutinhoRodrigues, "A Multiobjective Approach to Locate Emergency Shelters and Identify Evacuation Routes in Urban Areas 
Geographical Analysis Volume 41, Issue 1," Geogr. Anal., vol. 41, no. 1, pp. 9-29, 2009.

[6] J. Coutinho-Rodrigues, L. Tralhão, and L. Alçada-Almeida, "Solving a location-routing problem with a multiobjective approach: The design of urban evacuation plans," J. Transp. Geogr., vol. 22, pp. 206-218, 2012.

[7] W. Ping, L. Xiang, and W. Kening, "The Study on Optimization Location-Allocation of Emergency Shelter for Earthquake," no. May, p. 7708, 2015.

[8] O. Rodríguez-Espíndola, P. Albores, and C. Brewster, "GIS and Optimisation: Potential Benefits for Emergency Facility Location in Humanitarian Logistics," Geosciences, vol. 6, no. 2, p. 18, 2016.

[9] B. Saeidian, M. Mesgari, B. Pradhan, and M. Ghodousi, "Optimized Location-Allocation of Earthquake Relief Centers Using PSO and ACO, Complemented by GIS, Clustering, and TOPSIS," ISPRS Int. J. Geo-Information, vol. 7, no. 8, p. 292, 2018.
[10] BPBD Sumatera Barat, "Rencana Kontinjensi Menghadapi Tsunami Provinsi Sumatera Barat," Padang.

[11] C. G. Rawls and M. A. Turnquist, "Pre-positioning and dynamic delivery planning for a short-term response following a natural disaster," Socioecon. Plann. Sci., vol. 46, no. 1, pp. 46-54, 2012.

[12] Y. Song and X. Yan, "A method for formulizing disaster evacuation demand curves based on SI model," Int. J. Environ. Res. Public Health, vol. 13, no. 10, 2016.

[13] R. Patrisina, "Humanitarian logistics planning in Indonesia," Prince of Songkla University, 2016.

[14] R. Patrisina, N. Sirivongpaisal, and S. Suthommanon, "A logistical relief distribution preparedness model: response to a probable tsunami case study in West Sumatra, Indonesia," Ind. Eng. Manag. Syst. 